\title{
Reports of Four Cases of Hypertrophic Olivary Degeneration in King-Chulalongkorn Memorial Hospital from August 2010 to November 2011
}

\author{
Pra Urusopone M.D., Sasitorn Petcharunpaisan M.D., Sukalaya Lerdlum M.D. \\ Department of Radiology, King-Chulalongkorn Memorial Hospital, Bangkok, Thailand
}

\begin{abstract}
We report four cases of hypertrophic olivary degeneration (HOD), the first three cases after pontine hemorrhage from cavernous malformation, arteriovenous malformation (AVM) and hypertension and the latter one after surgery for removal of Non-Hodgkin lymphoma (NHL) involving dentate nucleus. The magnetic resonance (MR) features of all cases and diffuse tensor imaging (DTI) with fiber tractography findings in one case are described as well as discussion and review literature of this uncommon condition are performed.
\end{abstract}

Keywords: Hypertrophic olivary degeneration, Dentato-rubral-olivary pathway.

\section{Introduction}

Hypertrophic olivary degeneration (HOD) was first described by Oppentieim in $1887 .^{(1)}$ It is a transynaptic degeneration after injury to the neuronal connections in the dentatorubral olivary pathway or Guillian-Mollaret triangle (GMT) and is regarded as a unique morphologic type of neuronal degeneration because of hypertrophy rather than atrophy of the affected neurons within the inferior olivary nucleus $(\mathrm{ION}){ }^{(2)}$

Clinically patients may develop signature syndrome: palatomyoclonus or cyclic jerk at the soft palate, dentatorubral tremor or ocular nystagmus ${ }^{(3)}$

The MR imaging features are enlarged size and increased signal intensity $(\mathrm{SI})$ of the ION on T2- weighted image (T2 WI). On DTI there was a report of decreased volume and the fractional anisotropy (FA) value of the central tegmental tract at the same side of the affected ION by R. Shah et al in Oct 2010. ${ }^{(4)}$ Another report on 2011 also demonstrated dynamic changes of signal intensity and DTI parameters in all anatomic components of the affected GMT. ${ }^{(5)}$

For radiologists, familiarity with the characteristic features and understanding the pathophysiology of this degeneration will protect them not to misinterpret this condition as other lesions such as infarction, tumor or demyelinating diseases. In addition, recognization and prompt diagnosis of this condition lead to the appropriate counseling and treatment for the patients who may develop delayed symptoms. 
May-August 2013, Volume XIX No.II

\section{Results}

\section{Case 1:}

History : A 32 year old woman with history of bleeding cavernous hemangioma at right sided pons on January 1998. She had underwent suboccipital craniectomy with removal blood clot. Post operation she had developed right lateral rectus and facial palsy. She had lost follow up since 2003.

On October 2010, she went to the hospital because of vertigo and diplopia. On neurologic examination, she still had right sixth and seventh cranial nerve palsy. Left torsional nystagmus was also detected. No cerebellar sign or palatomyoclonus was observed.

Imaging : MRI of the brain showed a well defined oval shaped low SI on T1WI and hyper SI on $\mathrm{T} 2 \mathrm{WI}$ with hemosiderin rim at right lateral aspect of dorsal pons with minimal enhancement at the medial part, representing the prior residual bleeding cavernous hemangioma. (Fig.1) The right inferior olivary nucleus (ION) revealed iso $\mathrm{SI}$ on T1WI and hyper SI on T2WI and FLAIR without restricted diffusion or contrast enhancement, compatible with HOD. There was also left cerebellar atrophy. (Fig. 2)
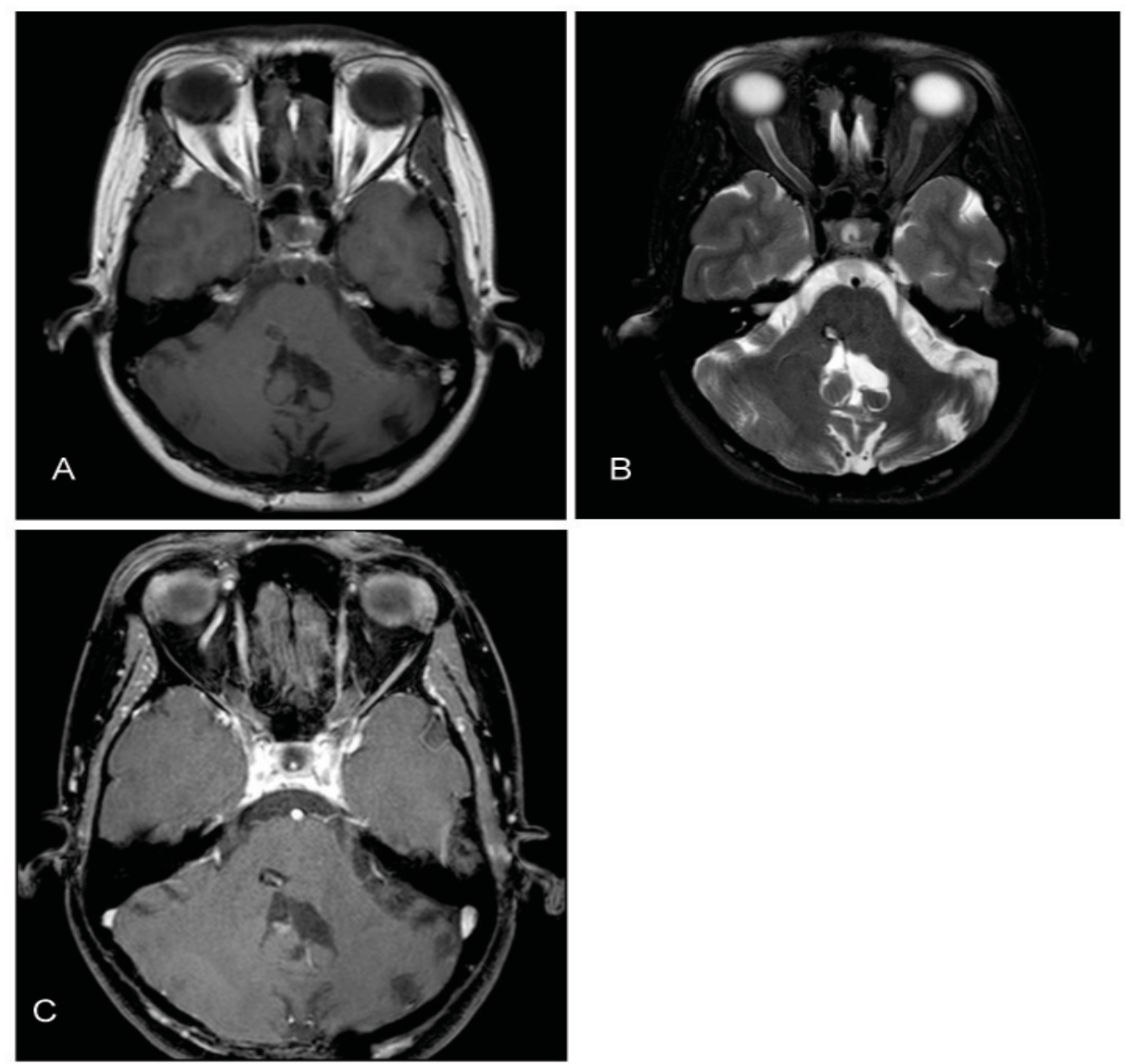

Fig.1 A) T1WI reveals : a well defined hypo SI with hyper SI rim at right sided dorsal pons.

B) T2WI : There is also a hemosiderin rim around the hyper SI lesion.

C) T1WI with contrast shows enhancement at medial part of the lesion.

The findings are compatible with previous bleeding cavernous angioma. 

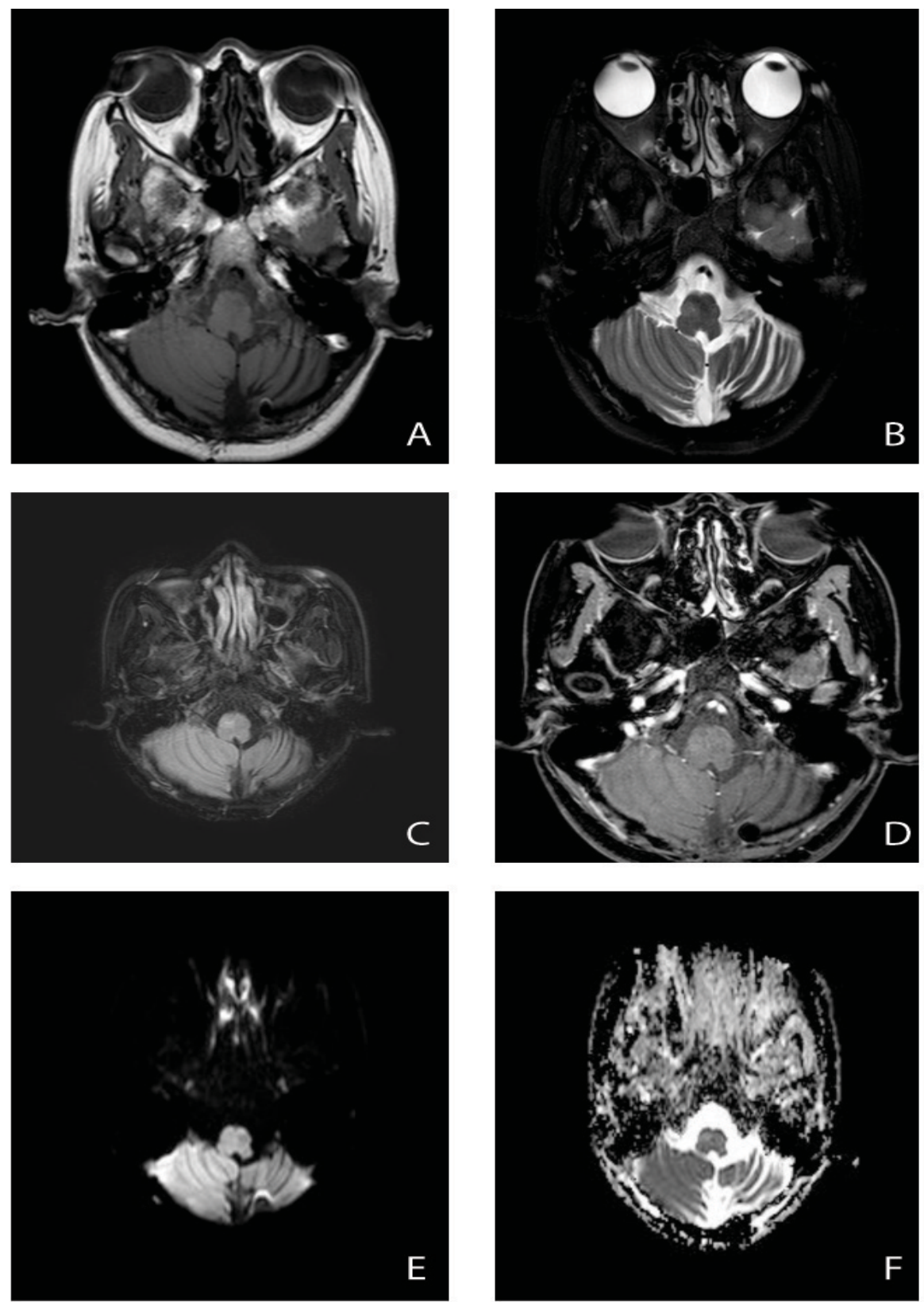

Fig.2 A-F : T1WI, T2WI, FLAIR, T1WI with CE,DWI and ADC reveal an iso SI lesion on T1WI, hyper SI on T2WI and FLAIR without contrast enhancement at right inferior olive. This lesion shows no restrict diffusion or enlargement, so HOD is compatible. There is also evidence of left cerebellar atrophy. 
May-August 2013, Volume XIX No.II

Case 2 :

History : A 30 year old man presenting with diplopia for 2 years after history of intracranial bleeding. On neurologic examination he had bilateral horizontal rotary nystagmus. No ataxia or palatomyoclonus was observed.

Imaging : MRI revealed a serpigenous flow void lesion at left sided pons and pontomedullary region and a well defined lobulated lesion with hypo
SI on T1WI, mixed hyper and hypo SI on T2WI and blooming SI on GRE T2* WI at left dorsal pons extending to left sided tegmentum of midbrain. DSA findings also demonstrated multiple feeding arteries and draining veins which are highly suggestive of AVM with previous bleeding. There was also evidence of left HOD, showing enlarged size of ION with iso SI on T1WI and hyper SI on T2WI. (Fig. 3)
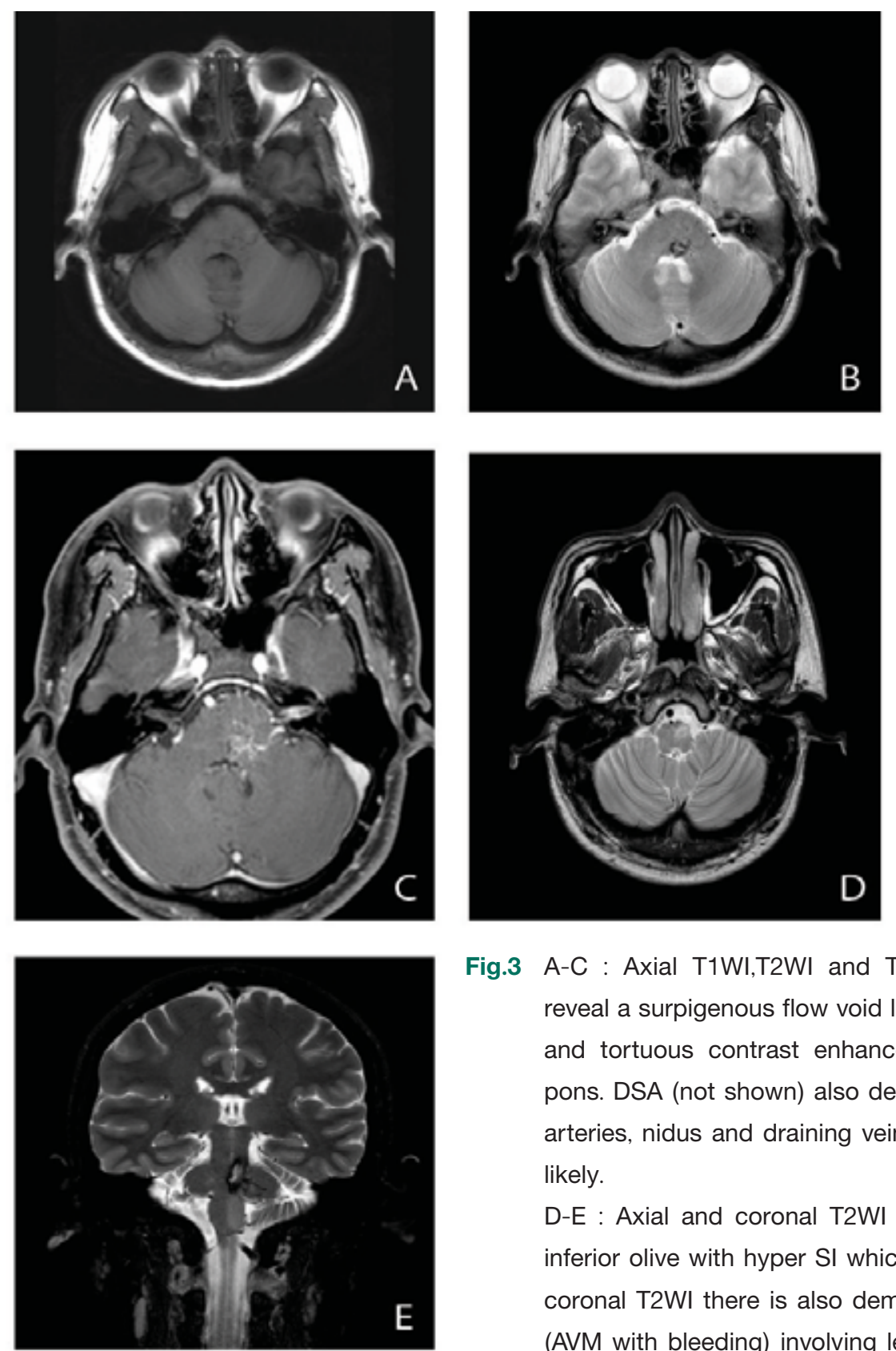

Fig.3 A-C : Axial T1WI,T2WI and T1WI with contrast studies reveal a surpigenous flow void lesions with hemosiderin rim and tortuous contrast enhancement at left sided dorsal pons. DSA (not shown) also demonstrates multiple feeding arteries, nidus and draining veins, so AVM with bleeding is likely.

D-E : Axial and coronal T2WI reveal enlarged size of left inferior olive with hyper SI which is suggestive of HOD. At coronal T2WI there is also demonstrated an inciting lesion (AVM with bleeding) involving left central tegmental tract. 
Case 3 :

History : A 75 year old woman with history of a right cerebellar mass detected on December 2009. The patient had had right suboccipital craniectomy with removal tumor. Post operation there had been hematoma at surgical bed. Pathologic result had concluded of NHL. So the patient had been treated by whole brain radiation. During follow up, the patient developed right facial palsy and right pronator drop without palatomyoclonus.
Imaging : First MRI on August 2010 had shown gliotic change at right cerebellum passing through right dentate nucleus without leptomeningeal enhancement. So post operative change without recurrent tumor had been concluded. There had been enlarged size of left ION with iso SI on T1WI and hyper SI on T2W, showing no restricted diffusion or contrast enhancement. (Fig. 4) Second MR findings of left ION on January 2011 were the same to the first study. So left HOD was diagnosed. (Fig. 5)
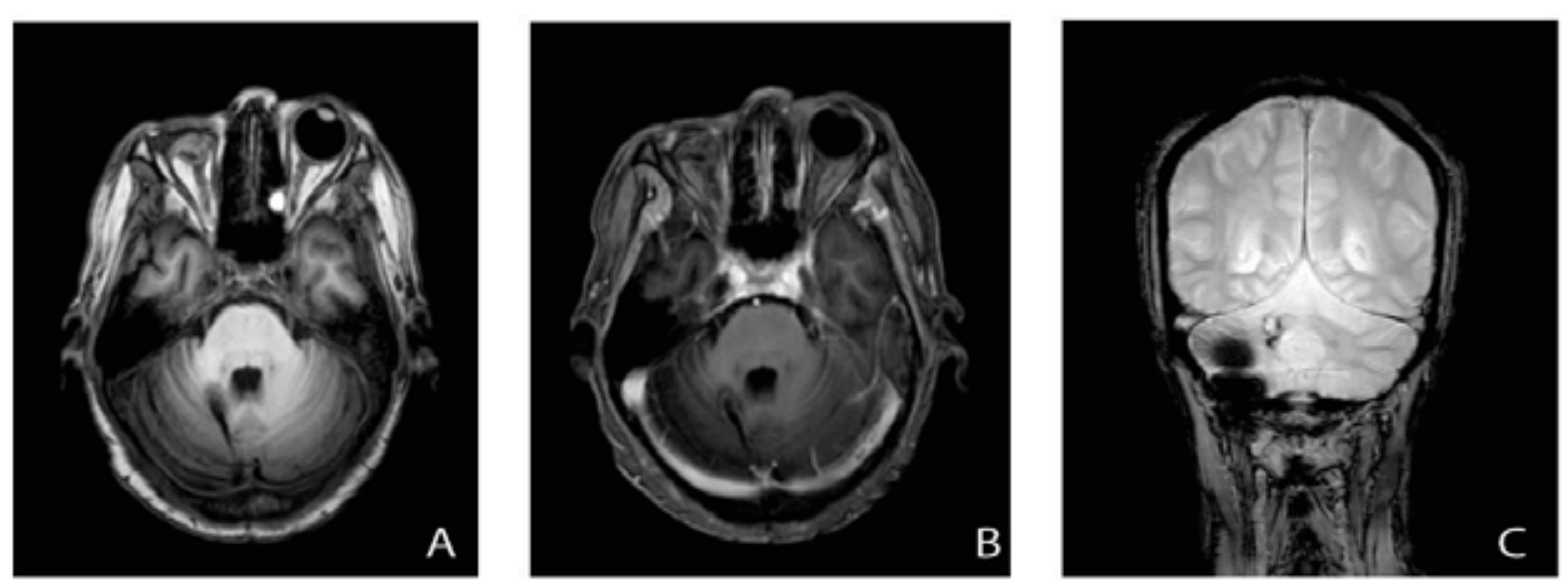

Fig.4 Case 3: First MRI : A-B ) Axial T1WI and T1WI with contrast : Evidence of slitlike hypo SI on T1WI without contrast contrast enhancement at right dentate nucleus is detected. C)Coronal GRE T2*WI also reveals hyper SI with blooming artifact. These findings are suggestive of encephalmalacia with previous bleeding . 

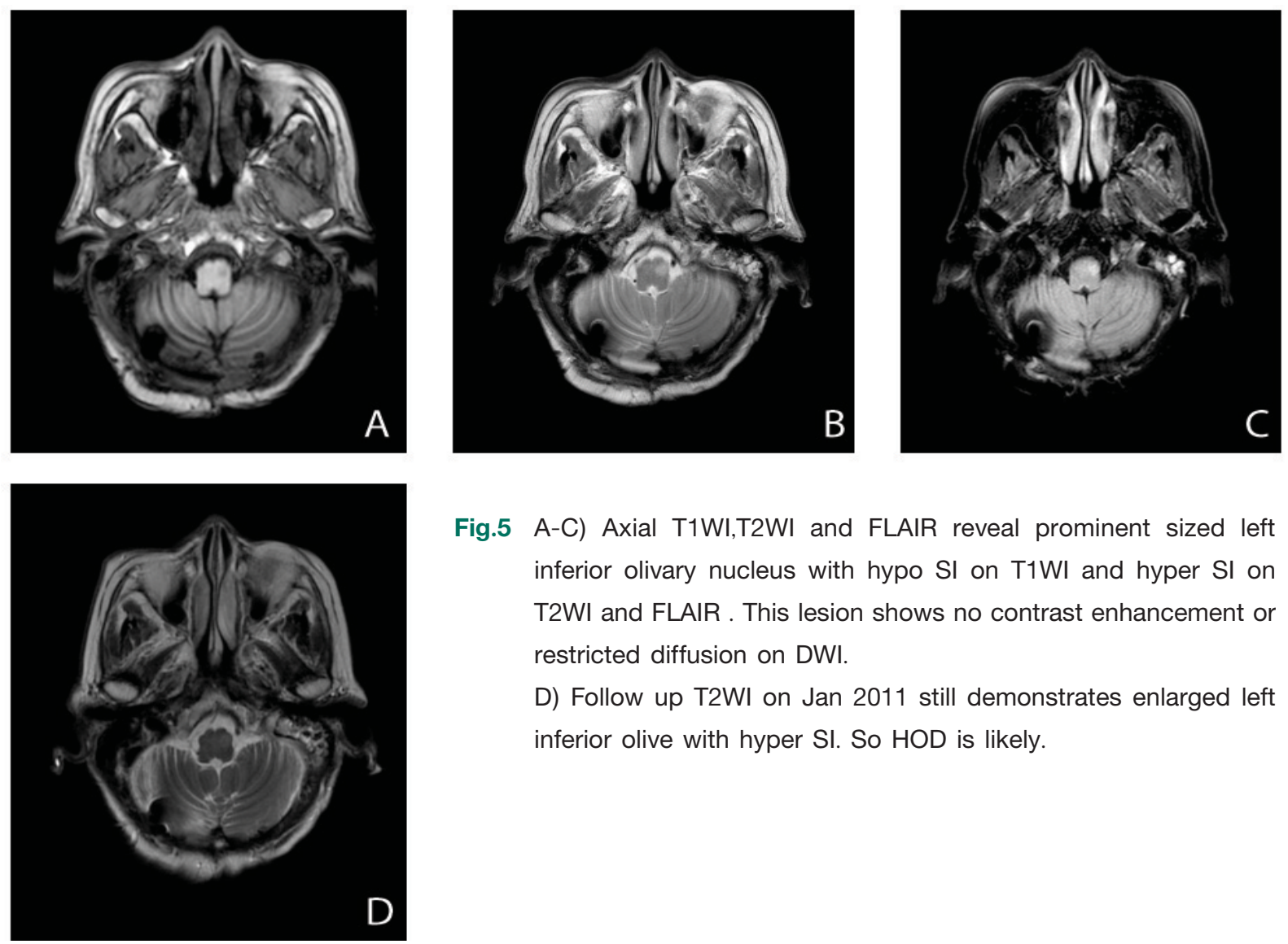

Fig.5 A-C) Axial T1WI,T2WI and FLAIR reveal prominent sized left inferior olivary nucleus with hypo SI on T1WI and hyper SI on T2WI and FLAIR. This lesion shows no contrast enhancement or restricted diffusion on DWI.

D) Follow up T2WI on Jan 2011 still demonstrates enlarged left inferior olive with hyper SI. So HOD is likely.

\section{Case 4 :}

History : A female, 64 year of age, with history of hypertensive pontine hemorrhage and a small right parasagittal meningioma two years ago. She had underwent craniectomy with removal the meningioma on February, 2010. Five months later, she presented with pontine hemorrhage again.

Imaging : CT findings on September, 2010 showed a hematoma at pons. (Fig.6) MRI on November 2011 revealed an evidence of hemosiderin deposit along transverse pontocerebellar fibers and dorsal part of pons which was compatible with prior pontine hemorrhage. Prominent size of left ION and signal intensity change representing HOD was also found (Fig.7)
DTI and fiber tractography were performed by placing regions of interest $(\mathrm{ROI})$ on axial slices at five levels. The first level at upper part of midbrain was used for ROI of both red nuclei and then fiber tractography were generated. Evidence of relatively thin left central tegmental tract was detected. (Fig.8) The second level at upper part of pons was used for ROI of both superior cerebellar peduncles. The third to fifth level were at pons through the fifth nerve entry zone for both central tegmental tracts, at medulla through the inferior cerebellar peduncle for both ION and at pons through the middle cerebellar peduncle for both dentate nuclei respectively. (Fig.9) The average FA and apparent diffusion 

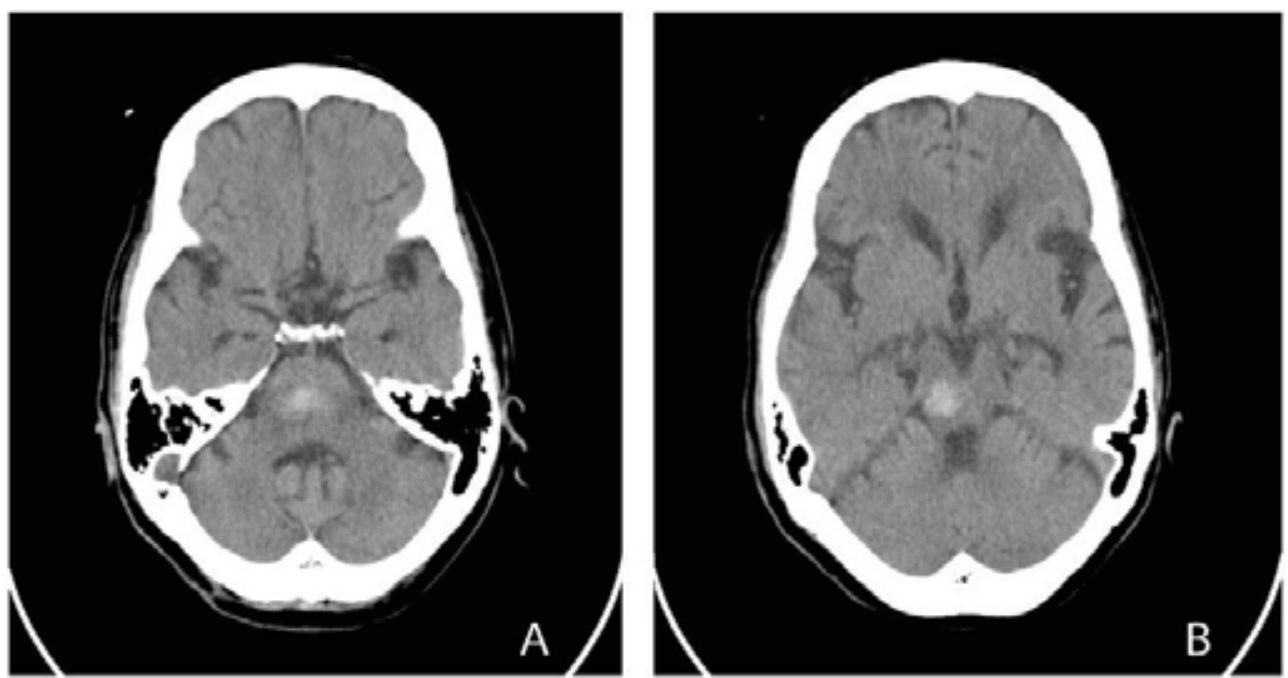

Fig.6 Case 4 A-B) Axial NCECT reveals a hematoma at dorsal pons and right sided midbrain
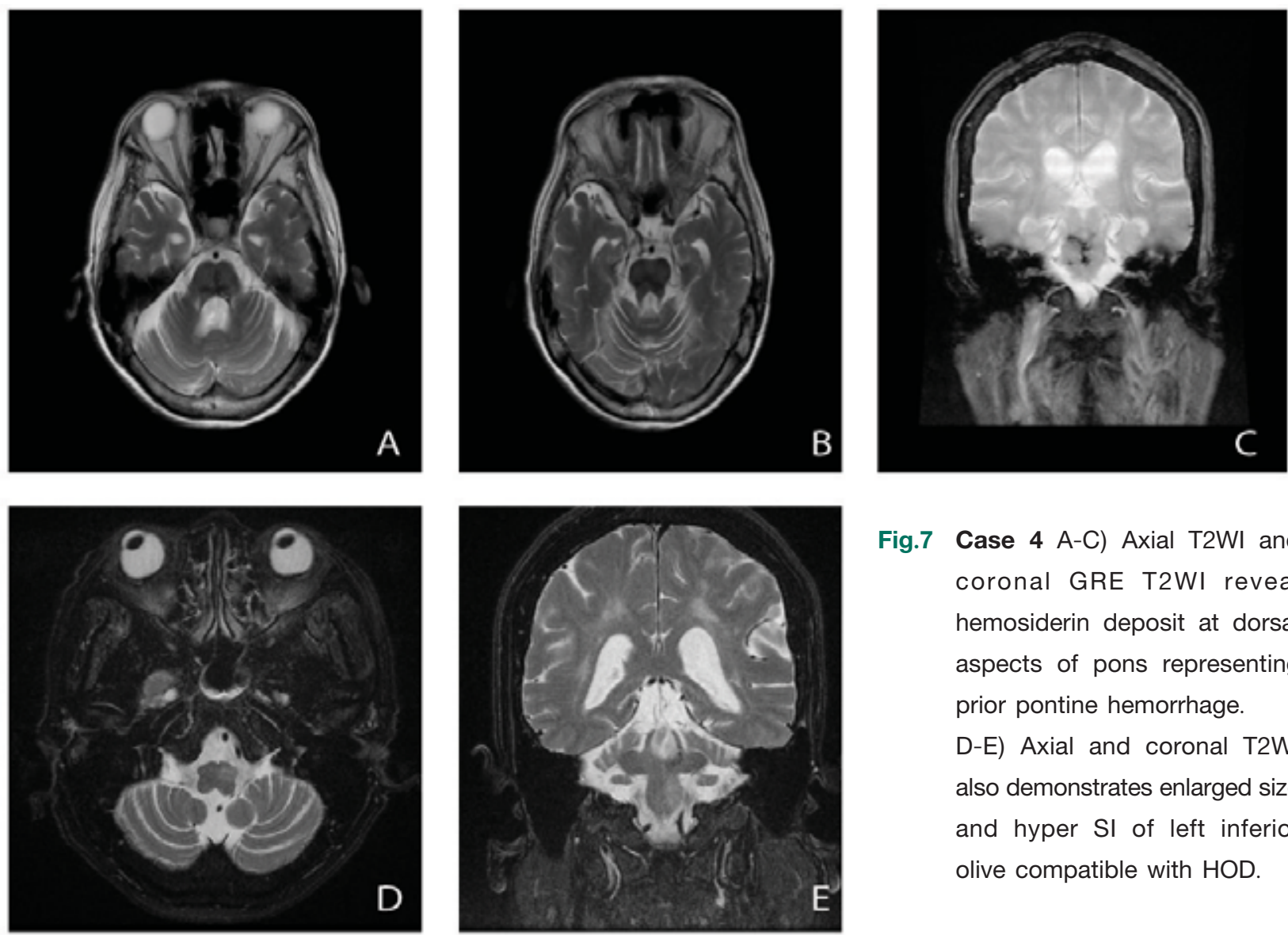

Fig.7 Case 4 A-C) Axial T2WI and coronal GRE T2WI reveal hemosiderin deposit at dorsal aspects of pons representing prior pontine hemorrhage.

D-E) Axial and coronal T2WI also demonstrates enlarged size and hyper $\mathrm{SI}$ of left inferior olive compatible with HOD. 

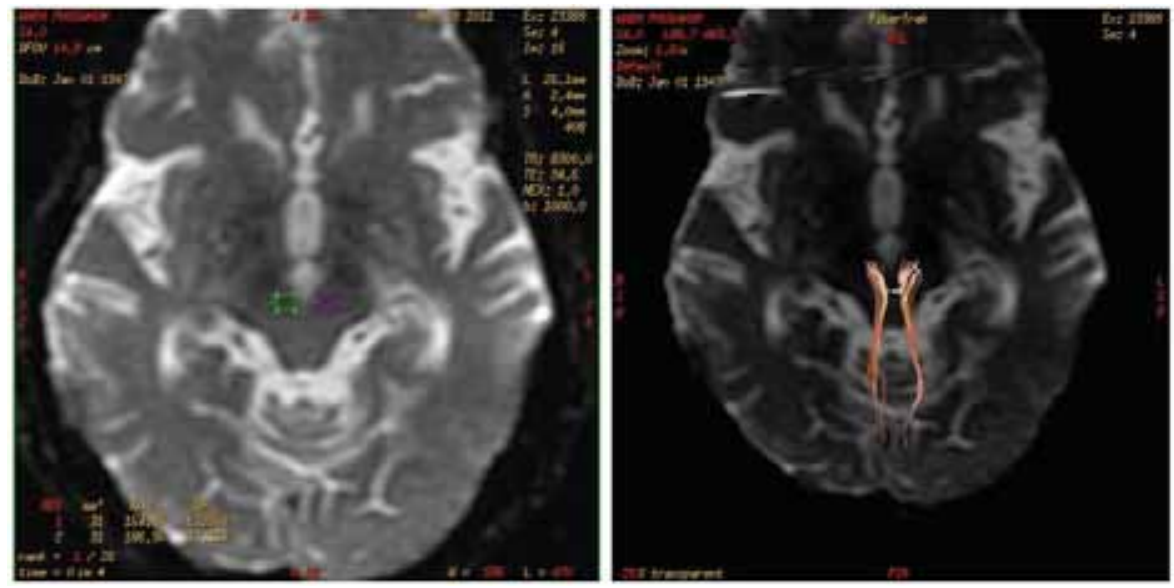

Fig.8 Fiber tractography performed by placing region of interest on both red nuclei . The study shows relatively thin left central tegmental tract.

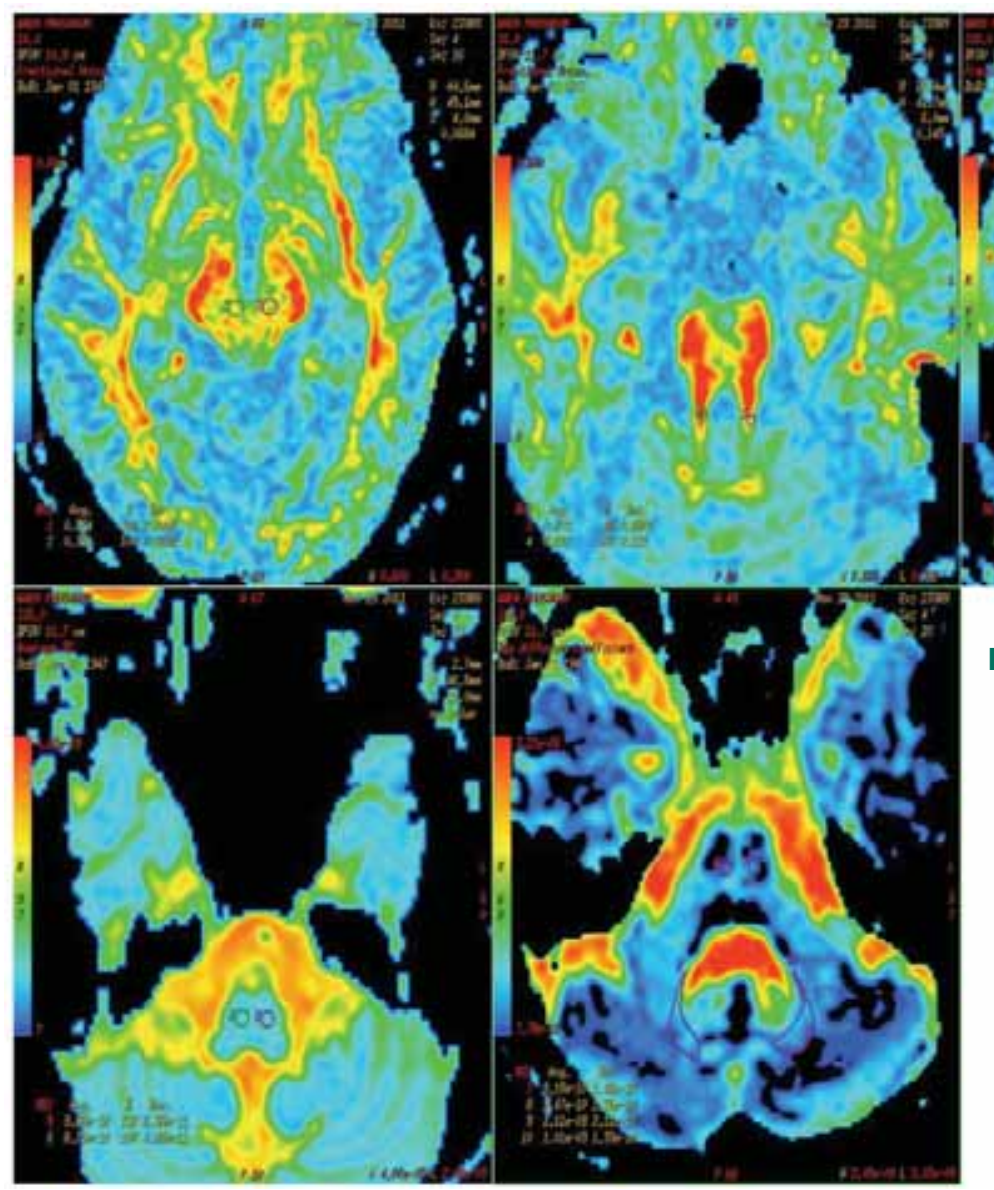

Fig.9 A-E demonstrates positioning of region of interest for $F A$ and $A D C$ on both red nuclei, superior cerebellar peduncles,central tegmental tracts, inferior olivary nuclei and dentate nuclei respectively. 
coeffcient $(A D C)$ values of five levels were calculated and summarized as table I.
Demographics and clinical profiles of all patients with HOD are summarized as table II.

Table I

\begin{tabular}{|c|c|c|c|c|}
\hline & \multicolumn{2}{|c|}{ Average FA } & \multicolumn{2}{c|}{ Average ADC } \\
\cline { 2 - 5 } Red nucleus & RT & LT (lesion) & RT & LT (lesion) \\
\hline $\begin{array}{c}\text { Superior } \\
\text { cerebellar } \\
\text { puduncle }\end{array}$ & 0.331 & $\begin{array}{c}0.354 \\
(106 \%)\end{array}$ & 8.67 & $\begin{array}{c}7.42 \\
(85 \%)\end{array}$ \\
\hline $\begin{array}{c}\text { Central } \\
\text { tegmental } \\
\text { tract }\end{array}$ & 0.597 & $\begin{array}{c}0.375 \\
(59 \%)\end{array}$ & 1.12 & $\begin{array}{c}1.56 \\
(138 \%)\end{array}$ \\
\hline $\begin{array}{c}\text { Inferior } \\
\text { olivary } \\
\text { nucleus }\end{array}$ & 0.243 & $\begin{array}{c}0.433 \\
(72 \%)\end{array}$ & 7.58 & $\begin{array}{c}8.64 \\
(114 \%)\end{array}$ \\
\hline $\begin{array}{c}\text { Dentate } \\
\text { nucleus }\end{array}$ & 0.234 & $\begin{array}{c}0.261 \\
(50 \%)\end{array}$ & 8.19 & $\begin{array}{c}9.88 \\
(120 \%)\end{array}$ \\
\hline
\end{tabular}

Table II

\begin{tabular}{|c|c|l|c|c|c|c|}
\hline $\begin{array}{c}\text { Patient } \\
\text { no. }\end{array}$ & Age/Sex & Inciting lesion and cause & $\begin{array}{c}\text { Palatal } \\
\text { tremor }\end{array}$ & $\begin{array}{c}\text { Time of MRI } \\
\text { after inciting } \\
\text { lesion }\end{array}$ & $\begin{array}{c}\text { Location of } \\
\text { HOD }\end{array}$ & $\begin{array}{c}\text { Hypertrophy in } \\
\text { ION }\end{array}$ \\
\hline 1 & $32 / \mathrm{F}$ & $\begin{array}{l}\text { Carvernous hemangioma } \\
\text { with bleeding at Right } \\
\text { sided pons }\end{array}$ & absent & 13 years & right & absent \\
\hline 2 & $30 / \mathrm{M}$ & $\begin{array}{l}\text { AVM at Left sided pons } \\
\text { and pontomedullary } \\
\text { region }\end{array}$ & absent & 2 years & left & present \\
\hline 3 & $75 / \mathrm{F}$ & $\begin{array}{l}\text { Removal of Right } \\
\text { cerebellar Non-Hodgkin } \\
\text { lymphoma }\end{array}$ & absent & $\begin{array}{c}1 \text { year/ } 8 \\
\text { months and 2 } \\
\text { years }\end{array}$ & left & present \\
\hline 4 & $64 / F$ & $\begin{array}{l}\text { Two episodes of } \\
\text { hypertensive hemorrhage } \\
\text { at 2 years and 2 months } \\
\text { before }\end{array}$ & $\begin{array}{l}\text { absent } \\
\text { episode or 2 } \\
\text { months of } \\
\text { recent } \\
\text { bleeding }\end{array}$ & left & present \\
\hline
\end{tabular}


May-August 2013, Volume XIX No.II

\section{Discussion}

HOD is a unique type of transsynaptic degeneration with hypertrophy of the affected ION. It represents to the end result of disruption of the components in GMT pathways. ${ }^{(6,7)}$ Common causes include bleeding injury (hypertensive, cavernous malformation or trauma), neoplasm and demyelination. ${ }^{(8)}$ This triangle was described by Guillian and Mollaret in $1931{ }^{(6)}$ It consists of three anatomical structures: the ipsilateral dentate nucleus in cerebellum, the contralateral red nucleus in the midbrain and ION in the medulla.

The afferent pathway originates in the contralateral dentate nucleus, passes over the superior cerebellar peduncle, crosses the midline through the inferior colliculi, enters the ipsilateral red nucleus and descends through the central tegmental tract to the ION. The efferent fibers from ION exits out of the hilus medially, crosses the midline and con- nects to the contralateral dentate nucleus through the contralateral inferior cerebellar peduncle : the olivocerebellar tract. (Fig. 10) ${ }^{(6)}$ Although the pathway has been described as a triangle, HOD is only the result of the disruption of the afferent fibers, less likely of the efferent ones. ${ }^{(9)}$

Knowledge of the components of the GMT is essential for understanding how the disruption can influence the ION. Three possible patterns of HOD are described. First the ipsilateral HOD occurs if the lesion involves the red nucleus or central tegmental tract. Secondly, when the lesion is at the dentate nucleus or the superior cerebellar peduncle, the contralateral HOD develops. Finally bilateral HOD appear in a paramedian lesion affecting both the central tegmental tract and the superior cerebellar peduncle or at the level of brachium conjunctivum where the decussation of bilateral GMT locates.

The major pathologic change of HOD includes

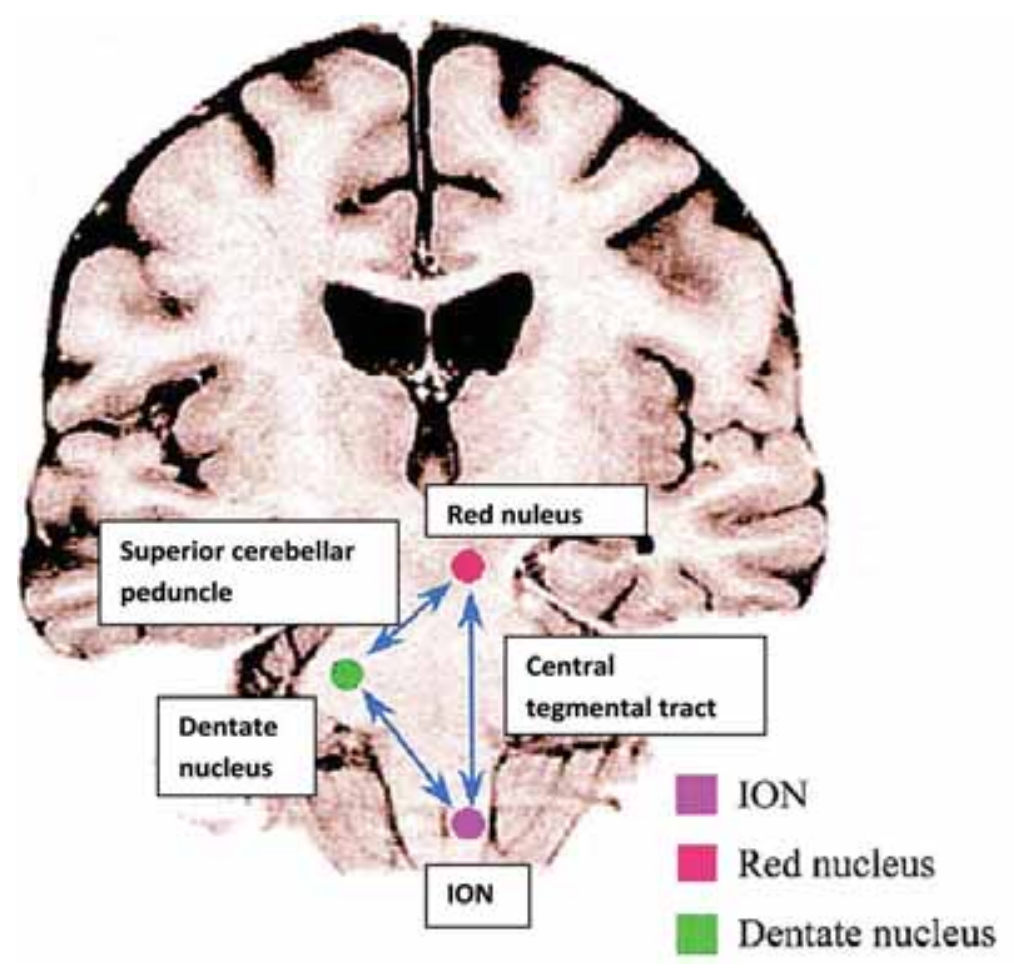

Fig.10 Diaphragm of dentatorubral-olivary pathway or Guillain-Mollaret triangle 
Table III Goto and Kaneko findings of HOD

\begin{tabular}{|l|l|l|l|}
\hline I & Pathologic stage & Timing & Pathologic findings \\
\hline II & Olivary amiculum & 24 hours & - \\
\hline III & $\begin{array}{l}\text { Mild olivary } \\
\text { hypertrophy }\end{array}$ & 3 weeks & $\begin{array}{l}\text { Degeneration of amiculum olive } \\
\text { Mild enlarged olive ,nueuronal hypertrophy } \\
\text { no gliotic reaction }\end{array}$ \\
\hline IV & $\begin{array}{l}\text { Maximal olivary } \\
\text { enlargement }\end{array}$ & 8.5 months & Hypertrophied neuron and astrocytes \\
\hline V & $\begin{array}{l}\text { Olivary } \\
\text { pseudohypertrophy }\end{array}$ & $>$ or $=9.5$ months & $\begin{array}{l}\text { Neuronal dissolution and gemistocytic } \\
\text { astrocyte }\end{array}$ \\
\hline VI & Olivary atrophy & Several years & $\begin{array}{l}\text { Neuronal disappearance and degeneration } \\
\text { of amiculum olive }\end{array}$ \\
\hline
\end{tabular}

vacuolar degeneration of the enlarged neurons, hypertrophy of the astrocytes and gliosis. The spectrum and predictable temporal microscopic changes in HOD was documented and categorized into six stages by Goto and coworker in 1981 and assessed correlation with MRI findings in 1994 by Mika Kitajima et al as summarized in table III. ${ }^{(10)}$

Three distinct MR stages and temporal evolution of the histopathology of HOD abnormalities have been demonstrated by Birbamer et al and Mayank Goyal and co workers. ${ }^{(11)}$

Stage 1: Increased SI on T2WI and Proton Density without hypertrophy of the olive which occurs at 1-6 months after onset.

This finding may relate to the $3^{\text {rd }}$ to $4^{\text {th }}$ classified by Goto in which gliosis and increased water content are associated with demyelination and vacuolization.

Stage 2: Hypertrophy and increased SI on T2WI which ends up as resolution of hypertrophy at 3-4 years after onset.

This stage is most likely the result of neuronal and astrocytic hypertophic precursors to cell death (stage $4^{\text {th }}-5^{\text {th }}$ of Goto et al)
Stage 3: Persistence of increased SI leading to atrophy of olive (stage 6th of Goto et al)

About DTI and fiber tractography studies, normal white matter anatomy in the brain stem has been described by several authors on MRI 1.5 and 3T system. The central tegmental tracts are symmetrical running in a superior-inferior directions. ${ }^{(12,13)}$

Decreased central tegmental tract volume away from the site of affected ION without deviation, deformation or interruption of tract in HOD has been reported. ${ }^{(4)}$ Dynamic change of signal and DTI parameters of all anatomical components in the GMT of HOD have also been studied which have shown the statistic significant increase in ADC of affected ION and other regions in GMT, excluding the inciting lesion. ${ }^{(5)}$

For our four cases, the remote inciting lesion, affected GMT, ION lesion, time evolution, possible pathologic classification by Goto et al and MRI stages are defined and summarized at Table IV.

All of the findings are compatible with previous reports of the causes of HOD (remote inciting lesion), pattern of pathway, disruption and temporal evolution with MRI findings. 
Table IV

\begin{tabular}{|c|c|c|c|c|c|c|}
\hline $\begin{array}{l}\text { Case } \\
\text { No. }\end{array}$ & Remote inciting lesion & $\begin{array}{l}\text { Affected } \\
\text { GMT }\end{array}$ & $\begin{array}{l}\text { ION lesion/ } \\
\text { hypertrophy }\end{array}$ & $\begin{array}{c}\text { Time } \\
\text { evaluation }\end{array}$ & $\begin{array}{l}\text { Pathologic } \\
\text { stage }\end{array}$ & MRI stage \\
\hline 1 & $\begin{array}{l}\text { Cavernous hemangiama } \\
\text { at Right sided dorsal pons } \\
\text { with prior hemorrhage on } \\
1998\end{array}$ & $\begin{array}{l}\text { Right } \\
\text { CTT }\end{array}$ & Right/ absent & 13 years & 6 & 3 \\
\hline 2 & $\begin{array}{l}\text { AVM at Left sided pons } \\
\text { and pontomedullary } \\
\text { junction and multistage } \\
\text { hemorrhage at Left sided } \\
\text { pons and Left tegmentum } \\
\text { of mid brain }\end{array}$ & Left CTT & Left/ present & 2 years & 5 & 2 \\
\hline 3 & $\begin{array}{l}\text { Post operative hematoma } \\
\text { after removal NHL at Right } \\
\text { dentate nucleus }\end{array}$ & Left GMT & Left/ present & 13 months & 5 & 2 \\
\hline 4 & $\begin{array}{l}\text { Repeated hypertensive } \\
\text { pontine hemorrhage }\end{array}$ & Left CTT & Left/ present & $\begin{array}{l}2 \text { years of } \\
\text { first } \\
\text { episode } \\
\text { and } 2 \\
\text { months of } \\
\text { recent } \\
\text { bleeding }\end{array}$ & 5 & 2 \\
\hline
\end{tabular}

GMT=Guillian-Mollaret triangle, $\mathrm{ION}=$ inferior olivary nucleus, CTT= central tegmental tract, $\mathrm{AVM}=$ arteriovenous malformation, $\mathrm{NHL}=$ non Hodgkin lymphoma

About the first patient, there was also left cerebellar atrophy, likely to be a crossed cerebellar diachisis. (CCD) $)^{(14)}$. This lesion resulted from an interruption of the cerebro pontine cerebellar tract . This tract receives axons from extensive areas of the cerebrum, passes through the cerebral peduncles, enters to the ipsilateral pontine nuclei and then runs to the contralateral cerebellum via the middle cerebellar peduncle. (Fig.11) $)^{(15)}$

In our patient, the old bleeding site also involved right middle cerebellar peduncle. So we postulated that this lesion might be from degeneration via right pontocerebellar tract. However, there was another report of cavernous angioma at left tectum of midbrain with left HOD and right cerebellar atrophy by Yunichi Komabe et al in 1997. ${ }^{(16)}$ Of their patient the lesion did not involve the ponto-cerebel- lar tract, so they postulated that it was caused by interruption of GMT.

Of the DTI study in the forth case, our findings of decreased DTI volume of the left central tegmental tract (affected tract) were the same as the case report in October 2010.(4) Decreased FA and increased ADC of affected left ION were also observed identical to the study of Alp. Dricer et al ${ }^{(5)}$

Increased ADC of left central tegmental tract and right dentate nucleus relatively to the contralateral side were also detected which the findings were the same as formentioned report, represent progressive demyelinative lesion of left GMT tract. We also detected increased ADC of left superior cerebellar peduncle and right red nucleus relatively to the contralateral side. This might be from recent bleeding involving left superior cerebellar peduncle 


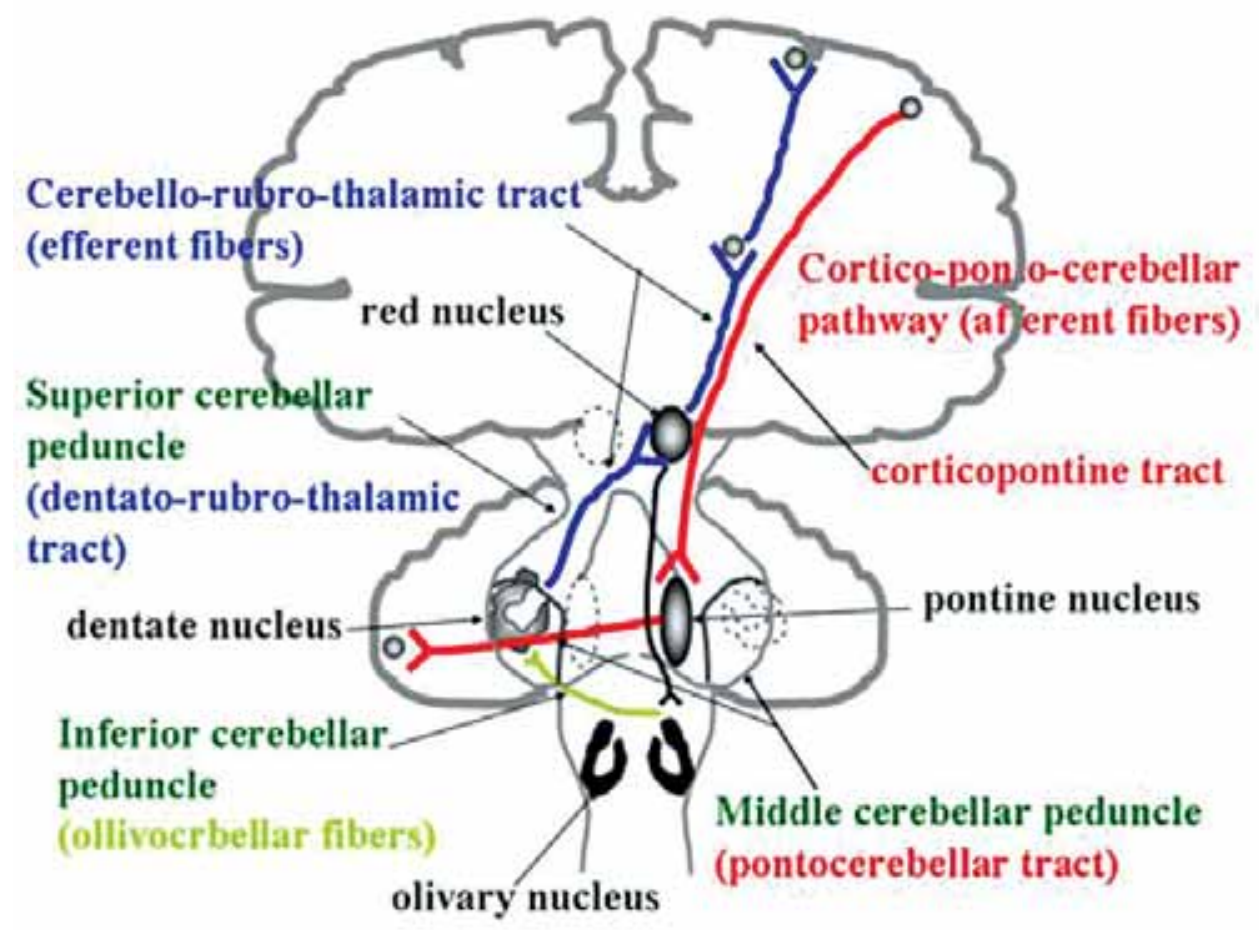

Fig.11 Diagram of corticopontocerebellar tract

which caused the degeneration of the components of right GMT tract (red nucleus). We postulated that there might be right HOD in the future.

However the study of DTI was limited because no control study of compatible white matter tract was available for comparison.

\section{Conclusion}

Hypertrophic olivary degeneration is a unique pathology with characteristic imaging manifestations. This process should be concerned when there is a non enhancing enlargement of the inferior olivary nucleus with T2 hyper signal intensity. Although these findings are non specific and can be seen in a wide variety of lesions including demyelination, infection, inflammation, infarction and tumor, lack of contrast enhancement, no restricted diffusion and evidence of an remote inciting lesion in the contralateral cerebellum or ipsilateral brainstem should lead to the diagnosis of HOD.

In addition to conventional MRI features, DTI and fiber tractography can demonstrate the disruption pathways of HOD and are useful for confirm diagnosis. Moreover, DTI parameters may reflect the temporal spatial progression of transneuronal degeneration in HOD. So further study of DTI in this rare condition needs to be performed. 


\section{References}

1) Oppenheim $\mathrm{H}$. Uber olivary degeneration bei atheroriatous der basalen hirniation. Berl Klin Wochenscher 1887;34: 638-9.

2) Durchen LW. General pathology of neurons and neuroglia. In : Greenfield H, Corsellis JAN, Duchen LW,eds. Neuropathology 4th ed. New York, NY:Wiley,1984;18-9.

3) Noriko Salamon-Murayma N, Russel EJ, Rabin BM. Case 17 :hypertrophic olivary degeneration secondary to pontine hemorrhage .Radiology 1999;213:814-7.

4) R.Shah, J.Market, A.K.Bag, J.K.Cure. Diffusion Tensor Imagine in Hypertrophic Olivary Degeneration. AJNR Am J Neuroradiol 2010;31:1729-31.

5) Alp Dincer, Onur Ozyurt, Dilava Kaya, et al. Diffusion Tensor Imaging of Guillian-Mollaret Triangle in Patients with Hypertrophic Olivary degeneration. J Neuroimaging 2011;21:145-51.

6) Goyal M, Versnick E, Tuite P, et al. Hypertrophic olivary degeneration : metaanalysis of the temporal evolution of MR findings. Am I Neuroradiol 2000;21:1073-7.

7) Kitajima M, Yukunori K, Shimomura O, et al. Hypertrophic olivary degeneration; MR imaging and pathologic findings. Radiology 1994;192:539-43.

8) Lorraine Ash, Ashok Srinivasan : Case of the Season : Hypertrophic Olivary degeneration. Seminars in Roentgenology 2008;02:171-2.
9) T Krings, H Foltys, I G Meister, J Reul. Hypertrophic olivary degeneration following pontine hemorrhage: hypertensive crisis or cavernous hemangioma bleeding? J. Neurol Neurosurg Pschiatry 2003;74:797-9.

10) Mika Kitajima, Yukunri Korogi, Osamu shimoura, et al. Hypertrophic Olivary degeneration : MR imaging and pathologic findings. Radiology 1994;192:539-43.

11) Mayank Goyal, Eric Versnick, Paul Tuite, Jean Saint Cyr, et al . Hypertrophic Olivary degeneration : Metaanalysis of the Temporal Evolution of MR findings. AJNR Am J Neuroradiol 2000;21:1073-7.

12) Nagae-Poetscher LM,Jiang H,Wakana $S$, et al. High resolution diffusion tensor imaging of the brain at 3T. AJNR Am J Neuroradiol 2004;25:1325-30.

13) Salamon N, Sicotte N,Alger G,et al. Analysis of the brainstem white-matter tracts with diffusion tensor imaging. Neuroradiology 2005;47:895-902.

14) Brodal A. Cerebrocerebellar pathways : Anatomical data and some functional implications. Acta Neurol scan Suppl 1972;51:153

15) B.M. Rabin, D.J.Hebel, N. Salamon-Murayama, E.J. Russel. Distal Neuronal Degeneration Caused by Intracranial Lesions AJR 1998;171:95-102.

16) Yuichi Kamaba, Tatsuya Nomoto, Shin Kitamura and Akiro Terashi. Cavernous Angioma with Olivary Hypertrophy and Contralateral Cerebellar Diaschisis. Internal Medicine 1997;36(7):504-7. 